\title{
Organizational Commitment: A Case Study of Egyptian Teachers Post Revolution
}

\author{
Mohamed Mousa ${ }^{1} \&$ Ruth Alas ${ }^{1}$ \\ ${ }^{1}$ Estonian Business School, Estonia \\ Correspondence: Mohamed Mousa, Estonian Business School, Estonia.
}

Received: May 25, 2016

Accepted: June 14, 2016

Online Published: June 28, 2016

doi:10.5430/ijba.v7n4p33

URL: http://dx.doi.org/10.5430/ijba.v7n4p33

\begin{abstract}
Owing to its effect on teacher performance, absenteeism, retention, and turnover, organizational commitment has received great attention over the past three decades. The concept offers an explanation for employees' anxiety, inefficiency, and carelessness during work. This study has focused on Sadat educational primary public school directory, in Menoufia, Egypt to determine the main factors affecting the level of teachers' affective, continuance, and normative commitment by conducting semi-structured interviews and a set questionnaire. It was found that teachers' normative commitment is higher than both their affective and continuance commitment. Furthermore, the analysis of the interviews showed that workplace spirituality dimensions, cultural diversity aspects, uncertainty issues, and organizational culture traits are the main determinants of teachers' organizational commitment.
\end{abstract}

Keywords: organizational commitment, workplace spirituality, cultural diversity, organizational culture, uncertainty

\section{Introduction}

Education is often considered vital to attaining progress and prosperity in any developing country (Malik \& Naeem, 2011). Erdogan (2004) indicates that due to the fact that the age we live in witnesses a continuous, diverse, and rapid change, schools should employ strategies that address the needs of our age. Moreover, and given the fact that schools are composed of people, they have to realize that teachers are a main component of their educational processes and that their continuity relies, to a great part, on the capability and quality of teachers (Alas \& Mousa, 2016).

Egypt is one of the developing nations that have tried to use education as a paradigm for achieving growth and reform (Mahrous \& Kortam, 2012 and Alas \& Mousa, 2016). Currently, the country is facing an immense struggle that may hinder the whole educational process. A high percentage of its teachers are leaving governmental schools in search for better opportunities in the private sector or gulf countries. Furthermore, without even leaving their school, they don't deliver a rational satisfactory performance in their schools. The matter that calls into question teachers' level of organizational commitment and the factors contributing to that level.

Since its existence, organizational commitment has become one of the premier management and behavior aspects because of its effect on the levels of absenteeism, turnover, and intentions to leave (Rajendran \& Raduan, 2005). Moreover, Chang (1999) and Mousa \& Alas (2016) highlight that an understanding of organizational commitment provides an explanation for employees' misuse of power, irresponsibility, inefficiency and the case of being careless in doing work. Organizational commitment often addresses the link between employees and their organization (Clercq \& Rius, 2007). Furthermore, it often interprets employees' modes of behavior in face of organizational crisis (Chang, 2002). Mayer and Allen (1990) have classified organizational commitment into three approaches: affective, continuance, and normative, and this research will later illustrate them in detail.

Given the importance of organizational commitment for Egyptian governmental schools, this research seeks to answer the following questions:

1. What are the levels of teachers' affective commitment, continuance commitment, and normative commitment in Sadat educational primary public schools directory?

2. What are the main factors affecting teachers' organizational commitment in Sadat educational primary public schools directory? 


\subsection{Significance of the Study}

As a psychological bond ties an employee to his workplace, the concept "organizational commitment" has gained currency over the last few years and has become a main cornerstone in both management and behavior sciences. Needless to say, organizational commitment has a significant impact on organizational tenure, performance, and success, as well as on employee satisfaction, level of engagement, citizenship behavior, level of turnover and level of absenteeism. This was maintained by a number of studies (e.g. Nehmeh, 2009; Cohen, 2013 ; Furaker \& Berglund, 2014 and Mousa \& Alas, 2016). Moreover, Allen and Meyer (1990) and Meyer and Allen (2000) studied the main approaches of organizational commitment and measured level of employees' organizational commitment in diverse workplace settings.

In general, the majority of studies on commitment were concerned with the level of employees' organizational commitment and the reasons some organizations want to increase the level of commitment among their employees. The present study has targeted a new angel of organizational commitment by empirically (qualitatively) investigating the main factors affecting teachers' level of organizational commitment. Hence, this research fills an important gap in management literature. It is needless to say that the findings of this research may also help in improving the educational performance of Egyptian teachers and subsequently benefit the whole educational process in Egypt.

\section{Theoretical Background}

\subsection{Organizational Commitment}

Over the past 30 years, the concept organizational commitment has gained a prevalence in both academic and management arenas. It has appeared in the early 1970s to assess employees' level of affective attachment to their employer (Kaur \& Sharma, 2015). As a result, it has gained a rapid popularity in the business world. Moreover, it has focused on individuals' behavior within their organization (Clercq \& Rius, 2007).

One of the first trials to conceptualize organizational commitment was made by Porter et al. (1974) by considering it as "an acceptance of the organizational goals, willingness to put the maximum effort on the part of organization, and a desire to maintain membership in the organization". In their seminal research article, Meyer and Allen (1990) have classified organizational commitment into three approaches: affective, continuance and normative.

\section{- Affective commitment}

This refers to an employee's emotional attachment to, integration with, and involvement with his organization (Bryant et al., 2007). Enriquez et al. (2001) elaborate that organizational objectives, vision, and level of freedom employees enjoy are three determinants for the level of employees' affective commitment. Perry (2004) points out that promoting healthy, friendly and supportive discussions with supervisors may positively affect the level of employees' affective commitment.

- Continuance commitment

This refers to an employee's perceived costs of leaving his organization (Bryant et al, 2007). Becker (1960) indicates that employees invest time, effort, health, money, and so on in their organizations. Such investments strongly affect their decisions and/or intentions to leave or remain in their organizations. Accordingly, Sharma \& Sinha (2015) maintain that an increase in employees' age and tenure within organizations raises their perceived cost of leaving it. Employees may also think about their pension, knowledge, job security, and unused vacations upon considering the decision to leave their jobs (Sharma \& Sinha, 2015).

\section{- Normative Commitment}

Reflects an employee's obligation to stay in his organization (Bryant et al, 2007). Organizational culture, rewards, punishments, and employee autonomy play a vital role in deciding the level of normative commitment (Meyer \& Allen, 1997; Chang, 2002; Haar \& Spell, 2004, and Sharma \& Sinha, 2015).

Given what has preceded, Buchanan (1974) defines organizational commitment as "a Partisan or affective attachment to the aims and values of an organization for its own sake". It can also be defined as a psychological state that promotes an employee's continuity with his organization and reduces the likelihood of his departure (Allen \& Mayer, 2000). Haim (2007) sees organizational commitment as "a rational behavior of employees, designed to protect their occupational and employment assets in terms of salary and benefits, and as a function of tenure".

Li, Ahlstrom, and Ashkanasy (2010) highlight that the importance of organizational commitment is derived from its strong impact on organizational performance and subsequently, organizational success. Abidin et al. (2010) indicate that only fully committed employees give their best efforts and fulfill their obligations and job responsibilities 
towards their organization. Accordingly, organizations that have committed employees don't face the struggles of absenteeism, turnover, intentions to leave and low performance levels (Kuruuzum et al, 2009).

In a different perspective, Haim (2007) raises the argument of whether or not the organizations should keep their long-term commitment/ contracts to their workplace despite the on-going technologization and globalization. He indicates that there is an growing trend towards downsizing and outsourcing of labor activities which may yield a need to restructure the meaning and measurement of the concept organizational commitment.

Using Albert Hirschman's (1970) model of voice and loyalty, employees can use a range of five behavioral modes of commitment in facing organizational crisis: Exit, voice, loyalty, neglect, and silence (Haim, 2007). Whereas, Atak (2009) maintains that the following elements are the main indicators of organizational commitment: accepting the organizational mission, adopting the organizational culture (values and behaviors), feeling and showing a desire to continue membership in the organization, and exerting maximum effort to achieve organizational goods.

\subsection{Egypt before and after January 2011}

From 1981 to January 2011, Egypt had Hosni Mubarak as a president. During his period of presidency, Mubarak was both the commander-in-chief of the armed forces and the commander-in-chief of the police force. He had the right to appoint the prime minister, security leaders, religious figures, and other high rank officials. Clearly, authoritarianism was the main feature of Mubarak's era (Bauer, 2011) simply because he had the right to veto legislature. Furthermore, parliament had little influence over the government. Indeed, the National Democratic Party (NDP), which was headed by Mubarak, controlled all aspects of the legislative processes. There were few opposition parties that exerted hardly any influence over the political processes in Egypt.

During the first ten years of Mubarak's rule (1981-1991), the Egyptian economy was based mainly on the public sector. The privatization process started in 1991 as a result of foreign aids and loans from the World Bank and the International Monetary Fund. It is needless to say that the expansion of the privatization process resulted in a high level of unemployment and high prices. That's why the Egyptian government signed trade agreements with many regional, international, and supra-international organizations such as Mediterranean North African trade agreement (MENA) to upscale its economic performance, motivate foreign investors, and promote tourism in Egypt. The authoritarian rule, bureaucracy, civil corruption, and mismanagement of public funds and resources all contributed to an unhealthy environment for foreign investment or economic development of any sort.

Despite several trials to boost Egypt's economic performance, a study made by the International Institute for Conflict Prevention and Resolution in 2009 highlights that approximately 17\% of Egypt's population lives below the poverty line. Increasing unemployment further adds to this dilemma. Zoubir (2000) elaborates that the bad Egyptian economic situation during Mubarak's era acted as an antecedent to social and cultural tensions and subsequently as a breeding ground for religious extremism.

Further affected by this dismal state, the social, cultural, and educational circles in Egypt also deteriorated. Bauer (2011) indicates that Mubarak was surrounded by an elite group of businessmen, military leaders, policemen, and high level executives of the National Democratic Party, who received various forms of privileges such as land, monopolies, and credits. Meanwhile, ordinary citizens suffered from different forms of ethnic, religious, political, economic, and social discrimination.

The first few weeks of 2011 witnessed a fundamental change in leadership and government in Egypt. Millions of Egyptian people hit the streets for three consecutive weeks calling for political freedom, social justice, and other rights. This historical break has remained open-ended and calls forth many questions, suggestions, and expectations for the rapidly changing Egyptian political scene. What is disturbing in this status quo is that street conflicts, torture, and the rising and diminishing of Islamic conservative parties have tended to become phenomenal of the daily life of the country.

Moreover, the complete withdrawal of the Egyptian police after January 2011 contributed to the spread of insecurity (Tabaar, 2013). Egyptian citizens formed vigilant committees all over big cities in Egypt. The situation of insecurity extended for more than two years and negatively affected the ability of the country to fight terrorism, organized crime, and regular strikes (Bauer, 2011). Accordingly, the Egyptian streets face from time to time what looks like civil wars.

A factor that contributed to the state of public unrest was the incompetent performance of the former Egyptian president, Mohamed Morsi, who was sworn in on 30 June 2012 to be the first democratically elected president of Egypt (http://edition.cnn.com/2012/06/30/world/africa/egypt-morsi/). Contrary to expectations, President Morsi was unable to foster an environment of equality, freedom, or true democracy as he had promised. During his era, the 
country was deeply divided into liberals and radical Islamic groups, women's rights were slowly disintegrating, and the peaceful state of coexistence among various Egyptian classes was threatened. These events fueled a second revolution in June 2013 in which protestors aided by the military subsequently succeeded in ousting their leader again in order to draw a new roadmap towards true democracy as they claim (http://www.dailynewsegypt.com/2013/08/12/attitudes-in-the-post-tamarod-post-morsi-erapoll/ ). It is needless to say that Egyptian citizens subsequently elected AbdelFattah Al-Sisi, their former minister of defense, to be their president on the third of June 2014. They considered their choice as an integral step towards adopting the roadmap announced after taking Morsi down. Despite this roadmap and the new presidential elections, Egypt is still witnessing some violent street conflicts, strikes, and criminal terrorism attacks from time to time.

With this background in mind, it is clear that educational institutions suffered in silence in an atmosphere of political, social, and economic instability. With many teachers being under-paid in the public education system and with the dire condition of public schools all over the country, teachers' commitment and performance are challenged. In addition to the limited career prospects of public school teachers and the over-crowded classrooms, more and more of the highly talented and qualified teachers are opting to leave the public school sector in search for better prospects in the private sector or abroad.

\section{Research Design}

\subsection{Conceptual Framework}

This conceptual framework of the present study is based on a review of previous studies conducted to demonstrate the meaning of organizational commitment. The measurement of commitment with its three approaches (affective, continuance and normative) is used to determine the level of commitment of teachers in the Sadat primary public school directory, Menoufia, Egypt. The school was selected based on the ability of one of the researchers to reach and examine the teachers there.

\subsection{Survey Instruments}

To answer the first question: a quantitative study was employed. A questionnaire was used for collecting the primary data. Most of questions included in the questionnaire are based on established existing models with some modifications made to the original questions with regards to the cultural aspect of this study sample. The questionnaire prepared for this study contains two main sections: Demographic variables and organizational commitment. A five-point Likert scale is used for all items under organizational commitment.

- Section A: Demographic Variables: This involves questions about the personal information of the targeted respondents such as gender, age, marital status, level of income and organizational tenure.

- Section B: Organizational Commitment: It is based on Allen and Mayer's (1990) three dimensional model of organizational commitment. This section covers the three approaches of organizational commitment: affective, continuance and normative. And each of the three subscales involves eight items.

By dividing the population into homogenous subgroups and then taking a simple random sample from each subgroup, the researcher counts on stratified random sampling. Such adoption of stratified random sampling reduces any possible bias and at the same time ensures that the chosen simple random sample represents the general population.

Since teachers who are working in Egyptian public schools are classified into five categories: junior teachers, first class teachers, alpha first class teachers, expert teachers and finally senior teachers, the use of stratified random sampling guarantees that each subgroup is represented in the chosen sample.

Since it is difficult to determine the size of population in this case, the researcher has chosen to distribute 200 sets of questionnaires to the targeted respondents. Needless to say, the sets of questionnaire will be delivered in Arabic to match the abilities of all targeted respondents and to motivate them to respond.

As for the second question: the vice director of the Sadat directory sampled 15 teachers, whereas the researchers themselves used their personal relationship to find an additional five teachers. It was discovered during the interviews that the participants were totally unaware of the concept of organizational commitment and its repercussions on their school scene. It was observed that during the interviews the participants were reluctant to uncover critical details with regards to the school out of fear of giving a negative impression that may compromise their standing with their schools. Some even went to the extent of refusing to have their interviews recorded when they were informed that the researcher would record them. 


\subsection{Scope of the Study}

Teachers who are working at the Sadat primary public school, Menoufia Province, Egypt, represent the main population sample for this study. Their selection for this study owes to the fact that they represent the category of Egyptian teachers who are working in public schools and who are likely to opt for offers from private schools or to accept job offers from schools in the Gulf countries. In addition, it is worthy to be mentioned that the researchers was able to reach many teachers in this province on a one to one basis.

\subsection{Data Analysis}

In response to the first question, the SPSS Pearson correlation was adopted to get the results of hypotheses testing. The SPSS was used to show the normal descriptive statistics such as frequency distribution, mean, and standard deviation.

In response to the second question, detailed transcripts were made in which the contents of the interviews were typed out after conducting the interviews. It is needless to say that the most interesting findings and information derived from the transcripts were coded. Owing to the specific focus of this research, questions and answers of the research were related to one of the following concepts; namely, organizational commitment and Egyptian revolution. Moreover, the participants' answers were correlated to detect a pattern in the gathered data.

\section{Research Findings}

As previous stated, the researcher distributed 200 sets of questionnaires, and he received responses from 150 teachers. With the help of stratified random sampling, the researcher formed the following profiles to classify the respondents demographically (see Table 1).

Table 1. Respondents' profile

\begin{tabular}{|c|c|c|}
\hline Demographic Variables & Items & Count \\
\hline \multirow[t]{2}{*}{ Gender } & Male & 123 \\
\hline & Female & 27 \\
\hline \multirow[t]{7}{*}{ Age } & below 25 years & 15 \\
\hline & $26-30$ years & 30 \\
\hline & $31-35$ years & 30 \\
\hline & $36-40$ years & 25 \\
\hline & $41-45$ years & 20 \\
\hline & $46-50$ years & 20 \\
\hline & More than 50 years & 10 \\
\hline \multirow[t]{3}{*}{ Marital Status } & Single & 40 \\
\hline & Married & 74 \\
\hline & Other & 36 \\
\hline \multirow[t]{3}{*}{ Level of Education } & Bachelor & 100 \\
\hline & Bachelor + Diploma & 48 \\
\hline & Master & 2 \\
\hline \multirow[t]{5}{*}{ Level of Income } & EGP 1200 & 15 \\
\hline & EGP $1300-2500$ & 60 \\
\hline & EGP 2500-4000 & 65 \\
\hline & EGP 4000-5500 & 10 \\
\hline & Above 5500 & 0 \\
\hline \multirow[t]{6}{*}{ Organizational tenure } & Less than 1 year & 0 \\
\hline & $1-3$ years & 45 \\
\hline & 4-6 years & 55 \\
\hline & 7-9 years & 40 \\
\hline & $10-12$ years & 10 \\
\hline & Above 15 years & 0 \\
\hline \multirow[t]{2}{*}{ Religion } & Muslim & 145 \\
\hline & Christian & 5 \\
\hline \multirow[t]{2}{*}{ Work Bases } & Full time & 150 \\
\hline & Part time & 0 \\
\hline
\end{tabular}




\subsection{Reliability Analysis}

The Cronbach Alpha is used to assess the internal consistency of each of the variables used in the study. As depicted in Table 1, all variables have adequate levels of internal consistency, and they meet the acceptable standard of 0.60 (Sekaran, 2003). In this study, the Cronbach Alpha Coefficient is 0.870 (as shown in Table 2).

Table 2. Reliability analysis

\begin{tabular}{lll}
\hline Scale name & $\begin{array}{l}\text { Number } \\
\text { of items }\end{array}$ & $\begin{array}{l}\text { Coefficient } \\
\text { alpha values }\end{array}$ \\
\hline Organizational Commitment & 24 & 0.870 \\
\hline Affective commitment & 8 & 0.771 \\
Continuance commitment & 8 & 0.760 \\
Normative commitment & 8 & 0.801 \\
\hline
\end{tabular}

Although the present study was aimed to determine the level of organizational commitment approaches (affective, continuance and normative) demonstrated by the teachers in Sadat city primary public school directory, Menoufia, Egypt and the factors affecting organizational commitment in this educational directory after the Egyptian revolution (2011), the researcher unintentionally found himself responsible for evaluating the whole educational process practiced by the school. Consequently, the following are the answers to the questions of the research.

What are the levels of teachers' affective, continuance and normative commitment in Sadat educational primary public school directory?

To answer this question, the mean scores were computed. As seen in Table 3 below, the mean for teachers' affective commitment is 3.733 , the mean for teachers' continuance commitment is 3.3550 , and the mean for teachers' normative commitment is 3.7908. This means that the majority of teachers appeared to have higher levels of normative commitment in comparison to both affective and continuance commitment. Accordingly, teachers in this study seem to be committed because they feel an obligation to stay in their schools. This happens when people feel that their organizational values are the same as their personal values. As said before, aspects such as organizational culture, rewards, punishments, and employee autonomy play a vital role in deciding the level of normative commitment.

Table 3. Summary of the mean score analysis

\begin{tabular}{lll}
\hline Perception & Mean & Standard Deviation \\
\hline Organizational Commitment & & \\
Affective commitment & 3.7333 & 0.5083 \\
Continuance commitment & 3.3550 & 0.5436 \\
Normative commitment & 3.7908 & 0.5875 \\
\hline
\end{tabular}

What are the main factors affecting teachers' organizational commitment in Sadat educational primary public schools directory?

The researchers started their interviews by asking about the meaning of organizational commitment, and unfortunately they found a lack of understanding with regards to its meaning. The majority of interviewees refereed only to leaving their school. However, Abidin et al. (2010) indicate that organizational commitment is not only about absenteeism, intentions to leave and turnover but also about poor performance, misuse of power, irresponsibility, and inefficiency.

Veugelers et al. (2006) affirm that education is required not only to prepare students for society but also to ensure that the society is present in the form of teachers. However, based on interviews with the sampled teachers, the researchers have observed that the recruitment of school teachers depends on nepotism and close relations with key personnel rather than any other mechanism. This is assumed to be the reason behind the much uncertainty evident in 
the interviews on how cultural diversity is managed within this educational directory. Two of the interviewed teachers mentioned that there is still a difference in the way Muslims and Christians are seen and treated in their schools; they explained that only Muslims are currently occupying the leading positions in this educational sector. This phenomenon has increased particularly after the revolution of 2011 and the success of the Muslim brotherhood in the elections for Egyptian parliament and later on after President Morsi who belongs to the Muslim brotherhood party won in the presidential elections. They also added that their schools don't provide any training for them to effectively manage cultural conflicts. This last issue is an unwelcomed fact because these schools are working in a country which has witnessed subsequent revolutions and social movement towards democracy, and at the same time it is suffering from a lack of tolerance among some classes of the society (Alas \& Mousa, 2016). This climate would be ideal to foster initiatives (coaching, workshops and mentoring) that would develop a kind of awareness towards accepting cultural difference and supporting commitment in any organization or institution (Roberson et al., 2001). Unfortunately, this is not the case in Sadat educational primary public school directory. The matter that has a negative impact on teachers' level of organizational commitment as reported in the conducted interviews.

Another important point that deserves to be mentioned is that teachers feel working in this climate do not do a meaningful job. Seven of the interviewed teachers asserted that they do not see any connection between their work and the social good of the community. One of the respondent said" I don 't experience any joy in my work and I don't feel that others like my work, I just come to work regularly in order to secure a salary at the end of the month". Three other interviewees highlighted that after the January 2011 revolution, personal growth of teachers no longer became a priority for their schools, and that their schools no longer care about the welfare of their teachers. These responses confirm, to a great part, that workplace spirituality dimensions (meaningful work, sense of community and alignment with organizational values) have become absent in the context of Sadat directory. This seems to be in line with what Cunha et al. (2008) maintained when they proved the significant correlation between workplace spirituality dimensions and organizational commitment. Accordingly, the dimensions of spirituality in Sadat's directory schools may represent a significant factor affecting teachers' organizational commitment after 2011's revolution.

Furthermore, a study made by Alas and Mousa (2016) confirmed that for a consistent organization to exist, personnel should constantly agree on its set organizational goals. One of the participants illustrated that he has no idea about his school's objectives in order to agree with them or not. Another one clarified that he cannot agree on his school/department goals without a kind of dialogue with his colleagues. However, he mentioned that he has started his position as a teacher from more than five years, and he never heard about an initiative for dialogue, meeting or conference in his school to discuss such a point although some of these aspects would have been available before 2011 as he clarified. Furthermore, two of the interviewed teachers expressed their desire to find a clear mission for their school but with a kind of involvement from the teachers' side. However, the strangest answer the researchers received was when one of the interviewees said: "I don't know who the director of Sadat City Primary Public School directory where I work is". This last comment by the interviewed teacher raises questions about the role organizational culture traits (involvement, consistency, adaptability and mission) play in the Sadat educational primary public schools directory after the January 2011 revolution and whether they still exist. It can be concluded that organizational culture traits come as a factor affecting teachers' organizational commitment in this educational directory. However, it is also questionable whether the directors of this educational directory take into account these organizational culture traits.

Finally two of the interviewees confirmed that what urges them to think about leaving not only their school but also the country is the climate of uncertainty that Egypt lives in. They feel worried about their country's security and economic soundness and sustainability on the one hand, and they feel the same worries towards their job roles, responsibilities, and the functions of their work units on the other hand. This falls in line with what was concurred by Song (2015) upon elaborating that uncertainty is the major challenge any public sector faces this era.

\section{Conclusion}

Although organizational commitment is a main part of the survival and continuity of any school, the researchers, having carefully, qualitatively, examined teachers of Public Primary Schools in Menoufia (Egypt), can confirm that they were not able to find a teacher centric approach by this schools in order to retain its teachers and/or enhance their level of organizational commitment. It is also statistically evident that teachers' level of normative commitment is much more than their levels of both affective and continuance commitment. Accordingly, teachers are committed because they feel an obligation to stay in their schools. This only happens when people feel that their organizational values are the same as their personal values. 
Given the conducted interviews, it seems that the aspects of workplace spirituality, cultural diversity, organizational culture and uncertainty also play a major role in shaping teachers' organizational commitment in the chosen educational directory.

It is needless to say that a full awareness of the institutional role school executives take on indicates a kind of integration with the political, economic, societal, and cultural changes existing in the surrounding environment. Accordingly, issues such as women empowerment, youth empowerment, religious equality, and tolerance should be listed in the agenda of any Egyptian school because of their impact on organizational commitment of teachers as evident from the conducted interviews.

Additionally, feeling worried and uncertain about both job related characteristics (job roles, responsibilities and promotion opportunities) and strategic aspects (country sustainability, security, and economic performance) are main determinants for a teacher's level of organizational commitment.

Finally, both organizational culture traits and workplace spirituality dimensions have appeared to be two key variables in not only deciding teachers' level of organizational commitment but also in the way their attitudes towards their job roles, career achievements and inner self-actualization are shaped.

\section{Limitations and Future Research Opportunities}

Some limitations of this study need to be brought to attention. First, owing to time constraints, it was not possible to conduct more than twenty interviews. From a methodological point of view, the answer to the second question is based mainly on the interviews. It appears that the participants mostly answered the interview questions in a rather normative and socially desirable manner. Accordingly, it is difficult for the researcher to verify the data even when relying on personal observations alone. However, future research could include a second data gathering instrument to evade this matter.

As a second methodological aspect, a remark regarding the participants has to be made. Unfortunately, it was not possible for the researchers to choose all the participants on a one to one basis. In this respect, Sadat educational primary public school directory was left to choose fifteen of its teachers. The researchers depended on their personal relationships to contact an additional number of participants because teachers themselves were not willing to take part in this research. This may be because they were not invited by the Sadat directory to participate.

It would also have added to the validity of results had the researcher avoided the Hawthorne effect during interviews by appointing an external interviewer. As such, interaction with participants may not be affected by the researcher's views or orientations and all biases would be avoided.

Another issue to consider is avoiding culturally biased and offensive questions that spur controversy or offense. This was done successfully in the selection and wording of the interview questions, and it is recommended that in future research all questions be screened for any biases or negative implications especially given the sensitive situation the country is in at the time of the research.

Finally, not everything said could be used as data. Sometimes, the interviewees emphasized that recording would be awkward and thus refrained from it. However, sufficient data is analyzed to give insights into the teachers' commitment level.

In sum, this study focuses on determining the level of affective, continuance and normative commitment in Sadat Educational Primary Public School Directory. It also extends to determine the factors affecting level of teachers' organizational commitment within this directory. Accordingly, it seems of great importance that further research studies are needed to clarify how the level of teachers' organizational commitment can be enhanced.

Coping with the fact that organizational commitment strongly affects the whole organizational performance and subsequently success, empirically examination of the effects of workplace spirituality, cultural diversity, organizational culture, and uncertainty on organizational commitment may help in building a human-centric approach for cultivating the current and future level of employees' organizational commitment; the matter that is so beneficial for an organization's continuity.

\section{References}

Abidin, S. N. S. Z., Muda, M. S., Hasan, F. A., \& Salleh, A. M. M. (2010). Organizational commitment in Malaysian public sector. IJMS, 17(1). Retrieved from http://www.ijms.uum.edu.my

Alas, R., \& Mousa, M. (2016). Cultural diversity and business schools' curricula: a case from Egypt. Problems and perspectives in management, 14(2) (cont.-1), 130-137. 
Alas, R., \& Mousa, M. (2016). Organizational culture and workplace spirituality. International journal of emerging research in management and technology, 5(3).

Allen, N., \& Meyer, J. (1990). The measurement and antecedents of affective, continuance and normative commitment to the organization. Journal of Occupational Psychology, 63(1). http://dx.doi.org/10.1111/j.2044-8325.1990.tb00506.x

Allen, N.J., \& Meyer, J.P. (2000). Construct validation in organizational behavior research: the case of organizational commitment. In Guftin, R.D and Helmes, E. (Eds.), Problems and solutions in Human Assessment: Honoring Douglas N. (pp. 285-314). Jackson at Seventy, Kluwer, Norwell, MA. http://dx.doi.org/10.1007/978-1-4615-4397-8_13

Atak, M. (2009). The relation between a learning organization and organizational commitment. Unpublished doctoral dissertation. Ataturk University, institute of social science.

Bauer, P. (2011). The transition of Egypt in 2011: A New Springtime for the European Neighborhood policy. $\begin{array}{lllll}\text { Perspectives on European Politics and } & \text { Society, }\end{array}$ http://dx.doi.org/10.1080/15705854.2011.622958

Becker, H. (1960). Notes on the concept of commitment. American Journal of Sociology, 66(1). http://dx.doi.org/10.1086/222820

Bryant, S., Moshavi, D., \& Nguyen, T. (2007). Afield study on organizational commitment, professional commitment and peer mentoring. Database for advances in information systems, 38(2). http://dx.doi.org/10.1145/1240616.1240622

Buchanan, B. (1974). Building organizational commitment. The socialization of managers in work organization. Administrative Science Quarterly, 22.

Chang, E. (1999). Career commitment as a complex moderator of organizational commitment and turnover intention. Human Relations, 43(10). http://dx.doi.org/10.1177/001872679905201002

Chang, E. (2002). Distributive Justice and organizational commitment revisited: moderation by layoff in the case of Korean employees. Human Resources Management, 41(2). http://dx.doi.org/10.1002/hrm.10035

Clercq, D. D., \& Rius, I. B. (2007). Organizational commitment in Mexican small and medium- sized firms: the role of work status, organizational climate and entrepreneurial orientation. Journal of Small Business Management, 45(4). http://dx.doi.org/10.1111/j.1540-627x.2007.00223.x

Cohen, R. (2013). Encyclopedia of management theory "organizational commitment theory". SAGE Publications, inc.

Dursun, E. (2015). The relation between organizational trust, organizational support and organizational commitment. African Journal of Business Management, 9(4).

Enriquez, V., Mc Bride, J., \& Paxton, L. (2001). Improving knowledge of strategic goals and the impact on organizational commitment. Health Mareting Quarterly, 18(3/4). http://dx.doi.org/10.1300/J026v18n03_09

Erdogan, I. (2004). Change management in education (2th ed.). Ankara, Turkey.

Furaker, B., \& Berglund, T. (2014). Job insecurity and organizational commitment. Revista international de organizacions, 13.

Haim, A. B. (2007). Rethinking organizational commitment in relation to perceived organizational power and perceived employment alternatives. International Journal of Cross Cultural Management, 7(2).

Harr, J., \& Spell, C. (2004). Programme knowledge and value of work. Family practice and organizational commitment. The international journal of human resources management, 15(6). http://dx.doi.org/10.1080/09585190410001677304

Hirschman, A. O. (1970). Exit, voice, loyalty. Cambridge, MA: Harvard university press.

Information about Egypt second revolution. Retrieved from http://www.dailynewsegypt.com/2013/08/12/attitudes-in-the-post-tamarod-post-morsi-erapoll/

Information about Egypt's former president. Retrieved from http://edition.cnn.com/2012/06/30/world/africa/egypt-morsi/ 
Kaur, J., \& Sharma, S. K. (2015). Measuring organizational commitment: scale validation for Indian financial services sector. The IUP Journal of Organizational Behavior, XIV(4).

Kuruuzum, A., Cetin, E. I., \& Irmak, S. (2008). Path analysis of organizational commitment, job involvement and job satisfaction in Turkish hospitality industry. Tourism Review, 64(1).

Li, Y., Ahlstrom, D., \& Ashkanasy, N. M. (2010). A multilevel model of affect and organizational commitment. Asia Pacific Journal of Management, 27. http://dx.doi.org/10.1007/s10490-010-9193-9

Mahrous, A., \& Kortam, W. (2012). Students' evaluations and perceptions of learning within business schools in Egypt. Journal of Marketing for Higher Education 22(1), 55-70.

Malik, M. E., \& Naeem, B. (2011). Role of spirituality in job satisfaction and organizational commitment among faculty of institutes of higher learning in Pakistan. African Journal of Business Management, 5(4).

Meyer, J., \& Allen, J. (1997). Commitment in the workplace- Theory research and application. Thousand oaks, CA: Sage Publications.

Meyer, J., \& Allen, N. (1991). A three- component conceptualization of organizational commitment. Human Resource Management Review, l(1). http://dx.doi.org/10.1016/1053-4822(91)90011-Z

Mousa, M., \& Allas, R. (2016). Cultural diversity and organizational commitment: A study on teachers of primary public schools teachers in Menoufia (Egypt). International Business Research 9(7).

Mousa, M., \& Allas, R. (2016). Workplace spirituality and organizational commitment: A study on the public schools teachers in Menoufia (Egypt). African Journal of Business Management, 10(10).

Mowday, R., Steer, R. M., \& Porter, L. W. (1979). The measurement of organizational commitment. Journal of Vocational Behavior, 14(2). http://dx.doi.org/10.1016/0001-8791(79)90072-1

Nehmeh, R. (2009). What is organizational commitment, why should managers want it in their workforce and is there any cost effective way to secure it? SMC working paper 5. Retrieved from www.swissmc.ch

Omar, K., Anuar, M. M., Majid, A. H. A., \& Johari, H. (2012). Organizational commitment and intention to leave among nurses: the mediating role of moral obligation. IJMS, 19(2). Retrieved from http://ijms.uum.edu.my/

Perry, R. (2004). The relationship of affective organizational commitment with supervisory trust. Review of Public Personnel Administration, 24(2). http://dx.doi.org/10.1177/0734371X03262452

Porter, L. W., Steer, R. M., Mowday, R., \& Boutin, P. V. (1974). Organizational commitment, job satisfaction, and turnover among psychiatric technicians. Journal of Applied Psychology, 59(2).

Rajendran, M., \& Raduan, C. R. (2005). Antecedents and outcomes of organizational commitment among Malaysian engineers. American Journal of Applied Science, 2(6).

Rego, A., \& Cunha, M. P. (2008). Workplace Spirituality and Organizational Commitment: An Empirical Study. Journal of Organizational Change Management, 21(1). http://dx.doi.org/10.1108/09534810810847039

Roberson, L., Kulik, C., \& Pepper, M. (2001). Designing effective diversity training: influence of group composition and trainee experience. Journal of Organizational Behavior, 22, 871-885. http://dx.doi.org/10.1002/job.117

Sekaran, U. (2003). Research methods for business. A skill building approach (4th ed.). United States of America: John Wiley and Sons.

Sharma, P., \& Sinha, V. (2015).The influence of occupational rank on organizational commitment of faculty members. Management, 20(2).

Tabaar, M. (2013). Assessing (In) security after the Arab spring: the case of Egypt. American Political Science Association, 10. http://dx.doi.org/10.1017/s1049096513001261

Veugelers, W., Derriks, M., \& Kat, E. (2006). Education and major cultural incidents in society: September 11 and Dutch education. Journal of Education, 3(2), 235-249. http://dx.doi.org/10.1080/17400200600874933

World Bank. (2009). Retrieved from http://data.worldbank.org/country/egypt-arab-republic

Zoubir, Y. (2000). Doing Business in Egypt. Thunderbird International Business Reviews, 42(2), 329-347. http://dx.doi.org/10.1002/1520-6874(200005/06)42:3<329::AID-TIE4>3.0.CO;2-R 